\title{
Individual-based primary prevention of cardiovascular disease in Cambodia and Mongolia: early identification and management of hypertension and diabetes mellitus
}

\author{
Dugee Otgontuya ${ }^{1 *}$, Sophal Oum², Enkhtuya Palam, Manju Rani ${ }^{3}$ and Brian S Buckley ${ }^{4}$
}

\begin{abstract}
Background: To assess the coverage of individual-based primary prevention strategies for cardiovascular disease (CVD) in Cambodia and Mongolia: specifically the early identification of hypertension and diabetes mellitus, major proximate physiological CVD risk factors, and management with pharmaceutical and lifestyle advice interventions.

Methods: Analysis of data collected in national cross-sectional STEPS surveys in 2009 (Mongolia) and 2010 (Cambodia) involving participants aged 25-64 years: 5433 in Cambodia and 4539 in Mongolia.

Results: Mongolia has higher prevalence of CVD risk factors than Cambodia -hypertension (36.5\% versus 12.3\%), diabetes (6.3\% versus $3.1 \%$ ), hypercholesterolemia ( $8.5 \%$ versus $3.2 \%)$, and overweight $(52.5 \%$ versus $15.5 \%)$. The difference in tobacco smoking was less notable (32.1\% versus $29.4 \%)$.

Coverage with prior testing for blood glucose in the priority age group 35-64 years remains limited (16.5\% in Cambodia and $21.7 \%$ in Mongolia). Coverage is higher for hypertension. A large burden of both hypertension and diabetes remains unidentified at current strategies for early identification: only 45.4\% (Cambodia) to 65.8\% (Mongolia) of all hypertensives and 22.8\% (Mongolia) to 50.3\% (Cambodia) of all diabetics in the age group 35-64 years had been previously diagnosed.

Approximately half of all hypertensives and of all diabetics in both countries were untreated. $7.2 \%$ and $12.2 \%$ of total hypertensive population and $5.9 \%$ and $16.1 \%$ of total diabetic population in Cambodia and Mongolia, respectively, were untreated despite being previously diagnosed.

Only $24.1 \%$ and $28.6 \%$ of all hypertensives and $15.9 \%$ and $23.9 \%$ of all diabetics in Mongolia and Cambodia, respectively were adequately controlled. Estimates suggest deficits in delivery of important advice for lifestyle interventions.
\end{abstract}

Conclusions: Multifaceted strategies are required to improve early identification, initiation of treatment and improving quality of treatment for common CVD risk factors. Periodic population-based surveys including questions on medical and treatment history and the context of testing and treatment can facilitate monitoring of individualbased prevention strategies.

\section{Background}

Non-communicable diseases (NCD) account for a growing proportion of morbidity and premature mortality worldwide. This public health problem is neither exclusively nor predominantly associated with high-income

\footnotetext{
*Correspondence: otgon_phi@hotmail.com

${ }^{1}$ Public Health Institute, Ministry of Health, Ulaanbaatar, Mongolia

Full list of author information is available at the end of the article
}

countries (HIC). The total number of NCD-related deaths is proportionate to the distribution of populations, with almost $80 \%$ occurring in low- and middleincome countries (LMIC). But this apparent parity masks the disproportionate impact of NCDs in LMICs. For example, in 2008, the age-adjusted NCD mortality rate per 100,000 people was 757 in low-income countries compared with 380 in HICs [1]. 
Cardiovascular disease (CVD) accounts for almost half of all NCD-related deaths and is the leading cause of death in the developing world. In LMICs nearly $58 \%$ of CVD deaths are in those under the age of 60 compared with just $20 \%$ in HICs [2]. The increasing CVD burden largely results from the increased prevalence of modifiable risk factors such as tobacco use, unhealthy diets, limited physical activity, elevated blood cholesterol and glucose levels and hypertension, which in turn are associated with a range of inter-linked social trends: changing life-styles, dietary habits, occupations, increasing urbanization, globalization and demographic changes [3].

In recent decades, either as part of routine health care or of specific CVD prevention programs, developed countries achieved reduction in CVD morbidity and premature mortality through combinations of three strategies: population-level primary prevention strategies (intended to reduce the burden of CVD by reducing overall levels of modifiable risk factors in the whole population); individual-based primary prevention strategies (health service and advice provision intended to prevent the onset of CVD through risk factor management in individuals with established CVD risk factors but no disease); and individual-based secondary prevention strategies (health service provision and advice intended to prevent disease progression in people with established CVD). Research from several countries has consistently shown that reductions in risk factors explain more of the decline in CVD mortality than treatments of established disease. Between $42 \%$ and $60 \%$ of the decline in CVD deaths has been attributed to changes in risk factors including reduction in total cholesterol, systolic blood pressure and smoking prevalence, while $23 \%$ to $47 \%$ was attributed to treatments and secondary preventive therapies [4-9]. Population-based and individual-based primary prevention strategies can complement one another, both contributing to changes in risk factors. Their relative contribution is difficult to ascertain, however, and appears to vary in different settings. While in the US, significant decreases in systolic and diastolic blood pressure among patients with hypertension between 1988-94 and 2007-08 have been attributed to better medical control, changes in dietary habits were considered a more likely explanation in Finland $[9,10]$. Regional variations aside, population and individual changes in modifiable risk factors can result in relatively rapid declines in CVD mortality [11].

This paper assesses the coverage of individual-based primary prevention strategies for CVD. In particular it considers the early identification and management of hypertension and diabetes mellitus, which are both major proximate risk factors for CVD. Recent research has highlighted very different levels of medical management of specific CVD risk-factors around the world but little evidence comes from low-income countries [12,13]. In addition, there is little evidence on utilization of nonmedical lifestyle interventions as part of targeted primary prevention strategies. Using nationally representative and comparable data from two LMICs in Asia, this study examines the prevalence of CVD risk factors and coverage of early detection and management of hypertension and diabetes mellitus through medical treatment, lifestyle modification interventions or both.

\section{Study context}

Throughout Asia, demographic and social changes have resulted in an epidemiological transition, from a total disease burden dominated by infectious disease to one dominated by NCDs. In many LMICs, this has resulted in a dual burden of infections diseases and NCDs and in many health systems are under-resourced and already stretched $[14,15]$. Thus both the challenge presented by NCDs and individual countries' capacities to address these challenges vary.

Two LMICs at different stages of transition are considered in this study. Mongolia, one of the least densely populated countries in the world with a population of less than 3 million is a lower-middle-income country with a growing economy centered on agriculture and mining. Cambodia, a low-income country of more than 13 million people, remains largely agricultural and rural $[15,16]$. In 2008, NCDs were estimated to account for almost $53 \%$ of life years lost in Mongolia, and 31\% in Cambodia [1].

\section{Methods}

The study uses data from STEPS surveys (STEPwise Approach to Surveillance) conducted in Cambodia and Mongolia (Table 1). STEP surveys are similar to National Health and Nutrition Examination surveys in wide use in many developed countries such as USA, Japan and South Korea [17-19]. They are cross-sectional nationally-representative surveys that combine interviews and physical examinations and use standardized questionnaires and measurement protocols. Aggregated results of both surveys have been published previously by internal national bodies [20,21].

Each survey used multi-stage stratified cluster random sampling to select participants 25-64 years old (15-64 years in Mongolia). Sampled individuals were interviewed in person to elicit information on selected demographic and socio-economic characteristics, tobacco and alcohol use, dietary intake, physical activity, and diagnosis and treatment history for diabetes and hypertension. The health examination part comprised of measurements of height, weight, blood pressure, resting pulse rate, and collection of blood samples. Cholesterol and blood glucose were measured for the whole sample in Cambodia and for every third respondent in Mongolia in the age group 25-64 years. For testing of blood glucose, participants 
Table 1 Survey sample sizes, sex and age, response rates and measurement methods

\begin{tabular}{|c|c|c|}
\hline & Cambodia & Mongolia \\
\hline Date of data collection & Feb - Apr 2010 & Oct-Dec 2009 \\
\hline \multicolumn{3}{|l|}{ Response rate } \\
\hline Questionnaire & $96.3 \%$ & $95 \%$ \\
\hline Physical measurements & $94.2 \%$ & $95 \%$ \\
\hline Biochemical measurements & $92.7 \%$ & $95 \%^{1}$ \\
\hline Sample size aged (25-64) & 5,433 & $4,539^{2}$ \\
\hline Male: \% (95\% Cl) & $48.6(47.2-50.1)$ & $50.3(48.2-52.3)$ \\
\hline Age in years: mean (SD) & $40.2(0.20)$ & $39.7(0.28)$ \\
\hline $\begin{array}{l}\text { Measurement of Blood pressure (measured } \\
\text { three times in sitting position) }\end{array}$ & NISSEl Digital Blood Pressure Monitor (Model DS-500) & $\begin{array}{l}\text { Omron Model } 5 \text { Automatic } \\
\text { Blood Pressure Monitor }\end{array}$ \\
\hline $\begin{array}{l}\text { Measurement of fasting Blood sugar and } \\
\text { cholesterol }\end{array}$ & $\begin{array}{l}\text { Whole capillary blood taken from fingertips; dry chemical } \\
\text { reagent strips \& Accutrend GCT instruments }\end{array}$ & Same as in Cambodia \\
\hline
\end{tabular}

were instructed to fast for at least 12 hours and not to consume anything except plain water. Participants on anti-diabetic medications were advised to refrain from taking these medications on the morning of the test but bring the medications with them to take after the testing was completed. The participants were advised to take any other medications as usual. Table 1 summarizes the sample sizes, response rates and measurement methods. All sampled adults provided written informed consent and the surveys were approved by National Ethics Committee for Health Research of Ministry of Health in Cambodia (number 132 NECHR dated December 4, 2009) and by the Medical Ethical Committee of the Ministry of Health in Mongolia (Number 13, dated August.3, 2009) The survey methodology has been described in detail elsewhere [20-22].

\section{Outcome variables: definitions}

The criteria by which prevalence is calculated for different NCD risk factors are presented in Table 2. We also report estimates of key service provision indicators-level of prior testing/diagnosis, and treatment as defined below.

\section{Screening coverage}

This indicator provides an estimate of the proportion of the population that is currently being tested for hypertension or diabetes, whether opportunistic, or in response to specific symptoms suggestive of hypertension or diabetes, or as part of a systematic screening program. The indicator was calculated for 35-64 years old population, as this group corresponds more closely with the ages for which guidance suggests screening is most important $[23,24]$. The question asked to assess prior testing was "have you ever had your blood pressure [blood sugar] measured by a doctor or other health worker?"

\section{Diagnosis coverage}

This indicator estimates the proportion of the hypertensive or diabetic population that is aware of their diagnosis. It reflects the net outcome of the coverage of screening and the degree to which this is targeted at high-risk individuals. The indicator is calculated as the proportion of total hypertensive (or diabetic) respondents as identified at the time of survey (using criteria and definition reported in Table 2) who reported positively to the question "have you ever been told by a doctor or other health worker that you have raised blood pressure or hypertension [blood sugar or diabetes]?".

\section{Treatment amongst hypertensives and diabetics}

Treatment status was elicited by a question: "Are you currently receiving any of the following treatments/advice for high blood pressure [diabetes] prescribed by a doctor or other health worker?" Response categories included medical treatment - "drugs (medication) that you have taken in past two weeks" (two separate categories for diabetes: insulin and other drugs) - and four non-medical categories - "advice to reduce salt intake" ("Special prescribed diet" for diabetes), "advice or treatment to lose weight", "advice or treatment to stop smoking", "advice to start or do more exercise". The denominator for assessing the treatment coverage includes both total hypertensive and diabetic population identified at the time of survey (as per the prevalence criteria in Table 2) or those who self-reported a previous diagnosis. It was considered important to include participants who self-reported a previous diagnosis but who were not classified as hypertensive or diabetic by blood pressure or glucose levels or by medication. This was so that analyses could take into account previously diagnosed individuals whose raised blood pressure or blood was managed through non-medical methods. Estimates are reported for the following: not receiving any treatment (either untreated despite 
Table $\mathbf{2}$ Criteria used to define and calculate prevalence of risk factors

\begin{tabular}{|c|c|c|}
\hline Risk factor variable & Definition/numerator & Denominator \\
\hline Diabetes prevalence & $\begin{array}{l}\text { Respondents with survey-measured fasting blood glucose } \geq 6.1 \mathrm{mmol} / \mathrm{l} / 110 \\
\mathrm{mg} / \mathrm{dl} \text { (whole blood); or measurement below threshold but respondent } \\
\text { reporting insulin or other medication. }\end{array}$ & $\begin{array}{l}\text { All respondents aged } 25-64 \text { with biochemical } \\
\text { measurements at time of survey }\end{array}$ \\
\hline $\begin{array}{l}\text { Hypertension } \\
\text { prevalence }\end{array}$ & $\begin{array}{l}\text { Respondents with systolic blood pressure } \geq 140 \mathrm{mmHg} \text { or diastolic blood } \\
\text { pressure } \geq 90 \mathrm{mmHg} \text { diastolic; or measurements below thresholds but } \\
\text { respondent reporting anti-hypertensive medication. }\end{array}$ & $\begin{array}{l}\text { All respondents aged } 25-64 \text { with } \\
\text { measurement of blood pressure at the time } \\
\text { of survey }\end{array}$ \\
\hline $\begin{array}{l}\text { Hypercholesterolemia } \\
\text { prevalence }\end{array}$ & $\begin{array}{l}\text { Measurement of total cholesterol } \geq 6.2 \mathrm{mmol} / \mathrm{l}(240 \mathrm{mg} / \mathrm{dl}) \text { at the time of } \\
\text { survey; or measurement below threshold but currently on medication for } \\
\text { raised cholesterol. }\end{array}$ & $\begin{array}{l}\text { All respondents aged } 25-64 \text { with } \\
\text { measurement of blood cholesterol at the time } \\
\text { of survey }\end{array}$ \\
\hline Physically underactive & $\begin{array}{l}\text { Physical inactivity assessed to be }<600 \text { MET (metabolic equivalent) minutes } \\
\text { per week as per the Global Physical Activity Questionnaire (GPAQ) scoring } \\
\text { protocol[22,25,26]. }\end{array}$ & All respondents aged $25-64$ years \\
\hline Overweight & Body Mass Index $\geq 25 \mathrm{~kg} / \mathrm{m}^{2}$ & $\begin{array}{l}\text { All aged } 25-64 \text { years with height and weight } \\
\text { measured (pregnant women excluded) }\end{array}$ \\
\hline Current smoking & $\begin{array}{l}\text { Respondents reporting positively to question "do you currently smoke any } \\
\text { tobacco product such as cigarettes, cigars, or pipes" }\end{array}$ & All respondents aged $25-64$ years \\
\hline
\end{tabular}

being previously diagnosed or untreated due to being undiagnosed prior to survey); currently treated (with the following subgroups: treated by drugs alone; treated by at least one of the non-medical treatments described above; treated or by both drugs and at least one of the non-medical treatments).

\section{Treatment quality deficits}

The proportion of the hypertensive (diabetic) population that reported they were on medication and who had blood pressure (blood sugar) higher than the diagnostic threshold at the time of survey was considered an indicator of suboptimal treatment quality. Proportions are also estimated of those with either condition who are overweight, physically underactive or current or previous smokers but who have not received appropriate advice about weight loss, exercise or smoking cessation respectively.

\section{Statistical analysis}

All the analyses were conducted using STATA Version 11. Percentages and 95\% confidence intervals were calculated for categorical variables. Using the "svy:" function in STATA, all estimated were weighted to correct for age-sex variation between samples and target national populations.

\section{Results}

\section{Prevalence of risk factors}

Mongolia has significantly higher prevalence of the major risk factors than Cambodia-hypertension (36.5\% versus $12.3 \%)$, diabetes (6.3\% versus $3.1 \%)$, hypercholesterolemia (8.5\% versus $3.2 \%$ ), and overweight (52.5\% versus $15.5 \%)$. The difference in tobacco smoking prevalence was less notable (32.1\% in Mongolia compared to $29.4 \%$ in Cambodia). However, Mongolia has a lower proportion of physical underactive population than Cambodia (6.5\% versus $9.0 \%$ ) (Table 3).

\section{Screening gap}

In both the countries, the proportion of individuals aged 35-64 who reported prior measurement of their blood pressure was substantially higher than for prior testing for blood glucose (Table 4). While almost three quarters of individuals reported previous measurement for blood pressure in Mongolia, about half of the respondents reported so in Cambodia. Similarly, the proportion of individuals whose blood glucose was previously measured was lower in Cambodia (16.5\%) compared to $21.7 \%$ in Mongolia.

\section{Diagnosis gap}

Consistent with higher screening coverage, proportions of total hypertensive individuals who were previously diagnosed were much higher in Mongolia (65.8\%) compared to Cambodia (45.4\%). However, despite the lower screening coverage for blood sugar in Cambodia, a significantly higher proportion of total diabetic individuals in Cambodia reported being previously diagnosed (50.3\%) than in Mongolia (22.8\%), which may suggest better targeting of testing to high-risk individuals in Cambodia (Table 4).

\section{Management of hypertension and diabetes}

Approximately half of the total hypertensive population in both countries, was untreated, though the proportion was higher in Cambodia (57.8\%) than in Mongolia (47.2\%) (Table 5). Of the total hypertensive population, $7.2 \%$ in Cambodia and $12.2 \%$ in Mongolia were untreated despite being previously diagnosed, $50.6 \%$ and $35.0 \%$ were untreated due to being undiagnosed. In Cambodia $13.8 \%$ and in Mongolia 17.0\% of hypertensives received non-medical treatments alone while $22.9 \%$ and $21.3 \%$ received both medical and non-medical treatments. At $14.6 \%$ the proportion receiving medical treatment alone was much greater in Mongolia than in Cambodia (5.4\%). 
Table 3 Prevalence of cardiovascular risk factors in population aged 25-64 in Cambodia and Mongolia

\begin{tabular}{|c|c|c|c|c|c|}
\hline Risk factor & Cambodia & & Mongolia & & \\
\hline & Number included in analysis & $\begin{array}{c}\text { Value } \\
{[95 \% \mathrm{Cl}]}\end{array}$ & Number included in analysis & $\begin{array}{c}\text { Value } \\
{[95 \% \mathrm{Cl}]}\end{array}$ & P-value (chi ${ }^{2}$ Pearson test) \\
\hline Current smoking (\%) & 5433 & $\begin{array}{c}29.4 \\
{[27.4-31.3]}\end{array}$ & 4539 & $\begin{array}{c}32.1 \\
{[30.3-33.9]}\end{array}$ & 0.04 \\
\hline Physically underactive (\%) & 5432 & $\begin{array}{c}9.0 \\
{[7.8-10.1]}\end{array}$ & 4470 & $\begin{array}{c}6.5 \\
{[4.3-8.6]}\end{array}$ & 0.04 \\
\hline Overweight (\%) & 5224 & $\begin{array}{c}15.5 \\
{[14.0-17.0]}\end{array}$ & 4501 & $\begin{array}{c}52.5 \\
{[49.7-55.3]}\end{array}$ & 0.00 \\
\hline $\begin{array}{l}\text { Hypertension prevalence - } \\
\text { survey measured (\%) }\end{array}$ & 5316 & $\begin{array}{c}12.3 \\
{[11.2-13.5]}\end{array}$ & 4502 & $\begin{array}{c}36.5 \\
{[34.2-38.8]}\end{array}$ & 0.00 \\
\hline $\begin{array}{l}\text { Diabetes prevalence - survey } \\
\text { measured (\%) }\end{array}$ & 5124 & $\begin{array}{c}3.1 \\
{[2.5-3.7]}\end{array}$ & 1470 & $\begin{array}{c}6.3 \\
{[4.5-8.0]}\end{array}$ & 0.00 \\
\hline $\begin{array}{l}\text { Hypercholesterolemia } \\
\text { prevalence\% }\end{array}$ & 5210 & $\begin{array}{c}3.2 \\
{[2.6-3.9]}\end{array}$ & 1538 & $\begin{array}{c}8.5 \\
{[5.3-11.7]}\end{array}$ & 0.00 \\
\hline
\end{tabular}

Slightly more than half of the total diabetic population in each country reported being untreated: $52.0 \%$ in Cambodia and $53.3 \%$ in Mongolia. In Mongolia nearly a third of these (16.1/53.4)were untreated despite previous diagnosis. This was the case for only one eighth (5.9/ 52.0) of untreated diabetics in Cambodia. At $25.8 \%$ the proportion of those receiving non-medical treatment alone in Mongolia was markedly higher than in Cambodia $(9.9 \%)$ (Table 5).

Only around a quarter $(28.6 \%$ and $24.1 \%)$ of the total hypertensive population and less than a quarter $(23.9 \%$ and $15.9 \%$ ) of the total diabetic population in Cambodia and Mongolia, respectively, had blood pressure or blood sugar levels that were controlled and less than the diagnostic thresholds upon survey measurement, including those on current medication.

\section{Treatment quality deficits}

More than two-thirds of hypertensive individuals receiving medications in Mongolia, and one-third in Cambodia had inadequately controlled blood pressure. Point estimates suggest deficits in delivery of key health advice to hypertensive individuals who are smokers, overweight or obese or physically underactive, but the small numbers included in analyses in many instances undermine the strength of these findings. Levels of uncontrolled blood glucose in diabetics on medication and poor advice levels among high-risk diabetic subgroups appear also to be of concern, but again low numbers of cases are available for analyses (Table 6).

\section{Discussion}

Using nationally representative data, this study assessed coverage of individual-based primary prevention strategies involving early detection and management of risk factors for CVD in two LMIC countries in Asia.

The study revealed key CVD risk factors already at alarming levels, with hypertension in particular emerging as a major public health concern. This high prevalence of risk factors warrants aggressive population-wide strategies such as public awareness campaigns and appropriate legislation and policy measures to alter societal norms relating to dietary salt intake, tobacco smoking and physical inactivity [27]. Individual-based primary prevention using medical and non-medical measures to

Table 4 Screening and diagnosis coverage for hypertension and diabetes in 35-64 years old population

\begin{tabular}{|c|c|c|c|c|}
\hline & \multicolumn{2}{|c|}{ Cambodia } & \multicolumn{2}{|c|}{ Mongolia } \\
\hline & Number included in analysis & $\begin{array}{c}\text { Value (\%) } \\
95 \% \mathrm{Cl}\end{array}$ & Number included in analysis & $\begin{array}{c}\text { Value (\%) } \\
95 \% \mathrm{Cl}\end{array}$ \\
\hline \multicolumn{5}{|l|}{ Hypertension } \\
\hline Previously tested & 3979 & $\begin{array}{c}51.3 \\
{[48.6-54.0]}\end{array}$ & 3014 & $\begin{array}{c}75.9 \\
{[73.8-78.0]}\end{array}$ \\
\hline Previously diagnosed & 695 & $\begin{array}{c}45.4 \\
{[40.3-50.4]}\end{array}$ & 1357 & $\begin{array}{c}65.8 \\
{[61.5-70.1]}\end{array}$ \\
\hline \multicolumn{5}{|l|}{ Diabetes } \\
\hline Previously tested & 3979 & $\begin{array}{c}16.5 \\
{[14.4-18.5]}\end{array}$ & 3014 & $\begin{array}{c}21.7 \\
{[18.8-24.6]}\end{array}$ \\
\hline Previously diagnosed & 173 & $\begin{array}{c}50.3 \\
{[40.6-60.0]}\end{array}$ & 67 & $\begin{array}{c}22.8 \\
{[6.9-38.6]}\end{array}$ \\
\hline
\end{tabular}


Table 5 Treatment among hypertensive and diabetic individuals aged 25-64 years in Cambodia and Mongolia

\begin{tabular}{|c|c|c|}
\hline & Cambodia & Mongolia \\
\hline & $\begin{array}{l}\text { Value (\%) } \\
(95 \% \mathrm{Cl})\end{array}$ & $\begin{array}{l}\text { Value (\%) } \\
(95 \% \mathrm{Cl})\end{array}$ \\
\hline Total hypertensive sample $(\mathrm{N})^{*}$ & (871) & (1938) \\
\hline i) Not treated\% & $57.8^{+}$ & $47.1^{\dagger}$ \\
\hline previously undiagnosed & $\begin{array}{l}50.6 \\
{[45.9-55.3]}\end{array}$ & $\begin{array}{l}35.0 \\
{[31.1-38.8]}\end{array}$ \\
\hline previously diagnosed & $\begin{array}{l}7.2 \\
{[5.3-9.1]}\end{array}$ & $\begin{array}{l}12.2 \\
{[9.7-14.6]}\end{array}$ \\
\hline ii) on treatment & $42.2^{\dagger}$ & $52.9^{\dagger}$ \\
\hline$\%$ only non-medical treatment & $\begin{array}{l}13.8 \\
{[11.1-16.5]}\end{array}$ & $\begin{array}{l}17.0 \\
{[13.9-20.1]}\end{array}$ \\
\hline$\%$ non-medical \& medical treatment & $\begin{array}{l}22.9 \\
{[19.2-26.7]}\end{array}$ & $\begin{array}{l}21.3 \\
{[18.6-24.0]}\end{array}$ \\
\hline$\%$ only medical treatment & $\begin{array}{l}5.4 \\
{[3.5-7.3]}\end{array}$ & $\begin{array}{l}14.6 \\
{[10.3-18.8]}\end{array}$ \\
\hline iii) Controlled & $\begin{array}{l}28.6 \\
{[24.7-32.5]}\end{array}$ & $\begin{array}{l}24.1 \\
{[21.0-27.2]}\end{array}$ \\
\hline Total diabetic sample $(\mathrm{N})^{*}$ & (208) & $(175)$ \\
\hline i) Not treated\% & $52.0^{+}$ & $53.4^{\dagger}$ \\
\hline previously un-diagnosed & $\begin{array}{l}46.1 \\
{[37.7-54.6]}\end{array}$ & $\begin{array}{l}37.2 \\
{[27.0-47.4]}\end{array}$ \\
\hline previously diagnosed & $\begin{array}{l}5.9 \\
{[2.2-9.6]}\end{array}$ & $\begin{array}{l}16.1 \\
{[8.4-23.9]}\end{array}$ \\
\hline ii) on treatment & $48.0^{\dagger}$ & $46.6^{\dagger}$ \\
\hline$\%$ only non-medical treatment & $\begin{array}{l}9.9 \\
{[6.0-13.9]}\end{array}$ & $\begin{array}{l}25.8 \\
{[18.5-33.1]}\end{array}$ \\
\hline$\%$ non-medical \& medical treatment & $\begin{array}{l}30.6 \\
{[23.2-38.0]}\end{array}$ & $\begin{array}{l}20.1 \\
{[11.6-28.5]}\end{array}$ \\
\hline$\%$ only medical treatment & $\begin{array}{l}7.5 \\
{[1.9-13.0]}\end{array}$ & $\begin{array}{l}0.7 \\
{[0.0-2.2]}\end{array}$ \\
\hline iii) \% controlled & $\begin{array}{l}23.9 \\
{[16.8-30.9]}\end{array}$ & $\begin{array}{l}15.9 \\
{[9.8-22.1]}\end{array}$ \\
\hline
\end{tabular}

* Includes both survey-measured and self-reported

${ }^{+}$Figures were rounded from five decimal points STATA outputs to one decimal point for the table. The sum of multiple rounded figures in the table may not exactly equal $100 \%$.

reduce risk factors in high-risk persons also needs to be scaled-up to complement population-wide measures.

Timely detection of underlying risk factors, a critical component of the individual-based primary prevention strategies, emerged as a major challenge. No formal guidelines for universal, targeted or opportunistic screening for CVD risk factors existed at the time of the surveys in both countries, though both prioritize early detection of NCDs in current national policy and program documents [16,28-30].

The results suggest that an improved proportion of cases might be detected by targeted testing. For example, while in Cambodia only $16.5 \%$ of $35-64$ year old population reported previous testing for blood sugar and yet $50.3 \%$ of total diabetic cases were previously diagnosed. Indeed, universal screening may not be feasible in many LMIC: evidence-based guidelines for opportunistic screening of high-risk population groups as identified based on epidemiological profile may be the first step, although poor overall health service utilization may limit coverage $[31,32]$. The frequent co-existence in individuals of several risk factors justifies strategies/guidelines for concurrent screening for multiple risk factors, an approach that also allows assessment of the absolute global risk of developing CVD in the next five to ten years-the recommended approach for making treatment decisions as discussed later [33].

The treatment gap in each country comprises those who are untreated because they are as yet undiagnosed, plus the proportion of individuals who are untreated despite previous diagnosis. In the absence of any follow-up questions, it is hard to identify the reasons for lack of treatment in these previously diagnosed hypertensives and diabetics, which may be both supply and demand related: due to factors related to difficulties in accessing or paying for treatment, and in some cases personal attitudes or preferences. 
Table 6 Specific treatment quality deficits in management of hypertension and diabetes

\begin{tabular}{|c|c|c|c|c|}
\hline \multirow[b]{2}{*}{ Indicator } & \multicolumn{2}{|l|}{ Cambodia } & \multicolumn{2}{|l|}{ Mongolia } \\
\hline & Number included in analysis & $\begin{array}{l}\text { Value \% } \\
(95 \% \mathrm{Cl})\end{array}$ & Number included in analysis & $\begin{array}{l}\text { Value\% } \\
(95 \% \mathrm{Cl})\end{array}$ \\
\hline \multicolumn{5}{|l|}{ Hypertension } \\
\hline On medication but blood pressure uncontrolled & 292 & $\begin{array}{l}38.5 \\
{[31.7-45.2]}\end{array}$ & 690 & $\begin{array}{l}68.8 \\
{[64.0-73.5]}\end{array}$ \\
\hline Smokers reporting no smoking cessation advice & 89 & $\begin{array}{l}34.7 \\
{[22.2-47.2]}\end{array}$ & 282 & $\begin{array}{l}54.8 \\
{[47.6-61.9]}\end{array}$ \\
\hline Overweight and reporting no weight loss advice & 141 & $\begin{array}{l}38.9 \\
{[29.4-48.4]}\end{array}$ & 761 & $\begin{array}{l}57.9 \\
{[50.7-65.1]}\end{array}$ \\
\hline Inactive and reporting no exercise advice & 48 & $\begin{array}{l}39.1 \\
{[21.9-56.2]}\end{array}$ & 98 & $\begin{array}{l}57.4 \\
{[44.8-69.9]}\end{array}$ \\
\hline \multicolumn{5}{|l|}{ Diabetes } \\
\hline On medication but blood sugar uncontrolled & 77 & $\begin{array}{l}58.1 \\
{[44.4-71.8]}\end{array}$ & 18 & $\begin{array}{l}61.9 \\
{[30.0-93.9]}\end{array}$ \\
\hline Smokers reporting no smoking cessation advice & 23 & $\begin{array}{l}13.2 \\
{[-2.4-28.9]}\end{array}$ & 29 & $\begin{array}{l}50.5 \\
{[25.0-76.1]}\end{array}$ \\
\hline Overweight and reporting no weight loss advice & 40 & $\begin{array}{l}18.2 \\
{[6.8-29.6]}\end{array}$ & 81 & $\begin{array}{l}40.2 \\
{[22.2-58.2]}\end{array}$ \\
\hline Inactive and reporting no exercise advice & 14 & $\begin{array}{l}20.6 \\
{[-1.1-42.2]}\end{array}$ & 10 & $\begin{array}{l}30.0 \\
{[-4.6-64.6]}\end{array}$ \\
\hline
\end{tabular}

A substantial treatment gap amongst the previously diagnosed population suggests that any plans to improve early diagnosis must be accompanied by increased provision, accessibility and affordability of treatment.

Approximately $14 \%$ and $17 \%$ of total of population with raised blood pressure and $10 \%$ and $26 \%$ of diabetics in Cambodia and Mongolia, respectively, reported receiving non-medical treatment alone. Such high proportions may reflect national guidelines that encourage utilization of non-medical lifestyle treatments in patients below recommended thresholds for initiation of medical treatments. But they may also in part reflect the reliance on nonmedical therapies in a subgroup of patients who cannot afford or access medical treatments.

Although guidance on diagnostic thresholds for initiating medical treatment may vary, non-medical interventions are recommended in all individuals at the diagnostic threshold used in this study [33,34]. In Mongolia 14\% of hypertensives reported receiving medical, but no non-medical treatments raising concerns about clinical practice. It appears that appropriate lifestyle advice that can improve management is not reaching many of these people.

The results suggest that diagnosis or initiation of treatment does not ensure effective disease management. Point estimates indicate worrisome levels of uncontrolled blood pressure and blood glucose among people on treatment and poor life-style advice levels amongst subgroups especially in need.

\section{Implications for service development}

Our findings for diagnosis gap and treatment coverage and quality are in line with other research that has drawn attention to suboptimal diagnosis and management of NCD risk factors. For example, some $70 \%$ of diabetics in seven countries in Europe, Asia and North and South America were assessed as failing to attain recommended blood sugar levels $[12,13]$. To reduce CVD mortality, a key goal of primary prevention strategies is to achieve a reasonable level of control of these risk factors. For example, one of the national objectives under Healthy People 2010 initiative in USA includes controlling blood pressure in $50 \%$ of all individuals with hypertension [10].

This study suggests that in Cambodia and Mongolia only about a quarter of all hypertension and less than a quarter of all diabetes is adequately controlled. Thus improvement in primary prevention strategies will require multifaceted efforts to improve detection and diagnosis, treatment of those diagnosed, and the quality of treatment among those who are treated In addition, our findings suggest improvements can be made in optimal use of nonmedical therapies.

Finally, the very high prevalence of risk factors as defined at the cut-offs levels used for each risk factor may imply need for substantial increase in health financing to provide drug treatment. Global absolute CVD risk assessment based on levels of multiple risk factors may be used to prioritize people with higher overall CVD risk for drug treatment, while those with lower overall risk may be followed-up with systematic life-style interventions. WHO and International Society for Hypertension has published cardiovascular risk prediction charts for all the fourteen WHO epidemiological sub-regions that can be used by physicians or non-physicians in lowresource settings to estimate 10 -year risk of a fatal or 
non-fatal cardiovascular event [33]. Recent research has suggested this approach offers substantial cost-saving in drug treatments [35]. Appropriate screening strategies will still be required for early identification of people with moderate to high absolute global CVD risk, but to date none of the countries have formally introduced clinical guidelines either for screening or treatment based on absolute CVD risk assessment, though Mongolia is in the process of developing these guidelines.

\section{Limitations}

The study has limitations that must be acknowledged. For example, due to the surveys' cross-sectional nature, whereas guidelines recommend that diagnosis should only be made on the basis of raised blood pressure sustained over time, the study diagnoses of hypertension are based upon multiple measurements at a single visit and thus may not be sufficient for a confirmed diagnosis or to assess the adequacy of control in individuals [16]. There may be inter-investigator variations in measurement that were not assessed in the survey and hence were not taken into account. The advice to refrain from the taking of diabetes medications on the morning of the blood tests may have delayed medication for some hours and affected readings in some participants. Adherence these and to fasting instructions is unknown. While the literature is consistent on suitability of capillary whole blood for screening of diabetes in population based surveys, the cut-off used to diagnose diabetes for capillary blood versus venous plasma is still debatable $[23,36]$. In the absence of any clear national guidelines in either of these countries, we used the most-commonly used cut-offs reported in international literature and guidelines. Measures of prevalence, diagnosis and treatment gap will vary greatly based on the diagnostic cut-off for hypertension and diabetes, though this methodology will still be appropriate to assess the trends in these indicators over time if similar measurement methods and diagnostic cutoffs are used. Finally, the study does not capture the complete disease burden that health systems may face, due to exclusion of population aged over 65 , which may have much higher disease burden.

\section{Implications for future surveys/research to monitor response to NCDs}

With regards to self-report of previous testing, it was not possible to ascertain whether individuals were tested previously as part of formal, opportunistic or universal screening programs or were simply tested when they sought services on experiencing symptoms. Nor can the source of testing be discerned: whether public or private or whether in primary or secondary care. Inclusion of questions on context of testing in future surveys may help to evaluate early detection strategies as more countries scale up NCD early diagnosis and care programs. Additional questions on adherence to treatment, cost and affordability of treatment and source of treatment may be included to distinguish and estimate the demand and supply-side factors affecting the treatment coverage. We were unable to examine the primary prevention of hypercholesterolemia due to lack of medical history for prior diagnosis and treatment. Considering the prominence given to high cholesterol levels in determining absolute CVD risk, the medical history for hypercholesterolemia may be included in future surveys.

\section{Conclusions}

The prevalence of risk factors for CVD is already at alarming levels in both countries. Only a small proportion of the total hypertensive or diabetic populations have adequately controlled blood pressure or blood sugar due to large diagnosis gap, non-treatment of previously diagnosed populations and inadequate control of treated population. Aggressive population-wide strategies complemented by individual-based primary prevention strategies will be required. Guidelines for concurrent screening of multiple risk factors in targeted population groups as identified based on epidemiological profile, which can be realistically delivered by health systems in these poorly resourced setting will be needed. Prioritization of individuals based on global CVD risk for drug treatment may reduce the overall cost of treatment. Non-medical treatment needs to be emphasized equally. Periodic population-wide surveys including questions on adherence to the treatment, reasons for not-seeking treatment, source and cost of the treatment, etc. should be conducted to better inform the programs and to monitor the performance of these efforts.

\section{Acknowledgements}

The authors would like to thank the STEPs survey teams and survey participants in Cambodia and Mongolia that made STEP surveys possible. The authors would also like to thank Dr. Ruth Bonita, Dr. Rebecca Dodd, and Dr. Henk Bekedam for their review and valuable feedback on the initial drafts. The authors also thank two reviewers- Chiara de Waure and Maximilian de Courten- for their valuable feedback and comments which helped to improved the paper substantially. No funding was obtained for carrying out the secondary analysis of STEPs survey data used in this study and for writing this manuscript by any of the first four authors. Dr. Brian Buckley, one of the coauthors who assisted with the writing and statistical analysis was paid under a contract by the Western Pacific Regional Office for World Health Organization.

Disclaimer

The views presented in this paper represent the views of the authors and not of the organizations they represent.

\section{Author details}

${ }^{1}$ Public Health Institute, Ministry of Health, Ulaanbaatar, Mongolia. ${ }^{2}$ University of Health Sciences, \# 73 Monivong Blvd, Phnom Penh, Cambodia. ${ }^{3}$ Western Pacific Regional Office, World Health Organization, Corner Taft and UN Avenue, Manila 1000, Philippines. ${ }^{4}$ Department of Surgery, Philippine General Hospital, University of the Philippines Manila, Philippines. 


\section{Authors' contributions}

$M R$ and $B B$ drafted the manuscript. EP and OD were the leading researchers for the STEPS survey in Mongolia and contributed to the conceptualization of the paper and writing. SO was the lead researcher for organization of STEPS survey in Cambodia, and contributed to the conceptualization of paper and writing. MR and BB carried out statistical analysis of the paper. All authors read, commented, and approved the final version of the manuscript.

\section{Authors' information}

EP -Public Health Institute, $\mathrm{MOH}$, Mongolia

SO - University of Health Sciences, Cambodia

$\mathrm{OD}$ - Public Health Institute, $\mathrm{MOH}$, Mongolia

MR - Western Pacific Regional Office, World Health Organization

BB - University of the Philippines, Philippines

\section{Competing interests}

The authors declare that they have no competing interests.

Received: 5 October 2011 Accepted: 2 April 2012 Published: 2 April 2012

\section{References}

1. World Health Organization: World Health Statistics 2011. Geneva World Health Organization; 2011.

2. Graziano TA: Reducing the growing burden of cardiovascular disease in the developing world. Health Aff 2007, 26(1):13-24.

3. World Health Organization: Noncommunicable disease and poverty. The need for pro-poor strategies in the Western Pacific Region: a review. Manila: World Health Organization, Western Pacific Region; 2006.

4. Capewell S, Beaglehole R, Seddon M, McMurray J: Explanation for the decline in coronary heart disease mortality rates in Auckland, New Zealand, between 1982 and 1993. Circulation 2000, 102(13):1511-1516.

5. Ford ES, Ajani UA, Croft JB, Critchley JA, Labarthe DR, Kottke TE, Giles WH, Capewell S: Explaining the decrease in US deaths from coronary disease, 1980-2000. N Engl J Med 2007, 356(23):2388-2398.

6. Kelly MP, Capewell S: Relative contributions of changes in risk factors and treatment to the reduction in coronary heart disease mortality (Briefing Paper) London: NHS Health Development Agency; 2004.

7. Palmieri L, Bennett K, Giampaoli S, Capewell S: Explaining the decline in coronary heart disease mortality in Italy between 1980 and 2000. Am J Public Health 2010, 100(4):684-692.

8. Unal B, Critchley JA, Capewell S: Explaining the decline in coronary heart disease mortality in England and Wales between 1981 and 2000 Circulation 2004, 109(9):1101-1107.

9. Vartiainen E, Laatikainen $T$, Peltonen $M$, Juolevi A, Mannisto $S$, Sundvall J, Jousilahti P, Salomaa V, Valsta L, Puska P: Thirty-five-year trends in cardiovascular risk factors in Finland. Int J Epidemiol 2010, 39(2):504-518.

10. Egan BM, Zhao Y, Axon RN: US trends in prevalence, awareness, treatment and control of hypertension, 1988-2008. JAMA 2010, 303(20):2043-2050.

11. Capewell S, O'Flaherty M: Rapid mortality falls after risk-factor changes in populations. Lancet 2011, 378(9793):752-753.

12. Gakidou E, Mallinger L, Abbott-Klafter J, Guerrero R, Villalpando S, Ridaura RL, Aekplakorn W, MNaghavi M, Lim S, Lozano R, et al: Management of diabetes and associated cardiovascular risk factors in seven countries: a comparison of data from national health examination surveys. Bull World Health Organ 2011, 89(3):172-183.

13. Roth GA, Fihn SD, Mokdad AH, Aekplakorn W, Hasegawa T, Lim SS: High total serum cholesterol, medication coverage and therapeutic control: an analysis of national health examination data from eight countries. Bull World Health Organ 2011, 89(2):92-101.

14. Miranda J, Kinra S, Casas JP, Davey Smith G, Ebrahim S: Non-communicable diseases in low- and middle-income countries: context, determinants and health policy. Trop Med Int Health 2008, 13(10):1225-1234.

15. World Health Organization: Western Pacific Country Health Information Profiles. Manila: World Health Organization, Western Pacific Region; 2011.

16. Ministry of Health: Clinical guideline on Arterial hypertension in adults. Ulaanbaatar: Ministry of Health $(\mathrm{MOH})$ of Mongolia; Millennium Challenge Account-Mongolia (MCA-M) Health Project; 2010.

17. Centers for Disease Control and Prevention: Nation Health and Nutrition Examination Survey.[http://www.cdc.gov/nchs/nhanes.htm].

18. Korea Center for Disease Control and Prevention: Korea National Health and Nutrition Examination Survey.[http://knhanes.cdc.go.kr/].
19. National Institute of Health and Nutrition: Outline for the results of the National Health and Nutrition Survey Japan, 2007. Tokyo National Institute of Health and Nutrition/Ministry of Health, Labour and Welfare; 2007.

20. Public Health Institute: Mongolian Steps Survey on the prevalence of noncommunicable disease and injury risk factors-2009. Ministry of Health, Mongolia; 2009.

21. Oum S, Prak PR, Khuon EM, Mey V, Aim S, Buonchan Y, Cin S, Pen L, Luon S: Prevalence of non-communicable disease risk factors in Cambodia: STEPS survey country report, September 2010 Phnom Penh: University of Health Sciences and the Ministry of Health; 2010.

22. World Health Organization: Chronic diseases and health promotion: STEPS Manual.[http://www.who.int/chp/steps/manual/en/index.html].

23. American Diabetes Association: Standards of medical care in diabetes 2012. Diabetes Care 2012, 35(Suppl 1):S11-S63.

24. World Health Organization: Guidelines for the prevention, management and care of diabetes mellitus. EMRO Technical Publications Series. Cairo WHO Regional Office for the Eastern Mediterranean 2006.

25. [http://www.ipaq.ki.se/ipaq.htm]

26. World Health Organization: Global Physical Activity Questionnaire (GPAQ) Analysis Guide. Geneva: World Health Organization; 2012.

27. Rose G: Sick individuals and sick populations. Int J Epidemiol 1985, 14(1):32-38

28. Government of Mongolia: National programme on prevention and control of non-communicable diseases Ulaanbaatar: Government of Mongolia. 2007

29. Ministry of Health: National Strategy for the Prevention and Control of Non-communicable Disease. Phnom Penh: Department of Preventive Medicine, Ministry of Health; 2007.

30. Ministry of Health: Health Strategic Plan 2008-2015. Accountability Efficiency Quality Equity. Phnom Penh Ministry of Health; 2008.

31. Ensor T, Cooper S: Overcoming barriers to health service access and influencing the demand side through purchasing Washington: The International Bank for Reconstruction and Development/The World Bank; 2004.

32. Jacobs B, Ir P, Bigdeli M, Annear PL, Van Damme W: Addressing access barriers to health services: an analytical framework for selecting appropriate interventions in low-income Asian countries. Health Policy Plan 2011.

33. World Health Organization: Prevention of cardiovascular disease: Guidelines for assessment and management of cardiovascular risk Geneva: World Health Organization; 2007.

34. World Health Organization: Preventing chronic diseases; a vital investment; WHO global report. Geneva World Health Organization; 2005.

35. Mendis S, Lindholm LH, Anderson SG, Alwan A, Koju R, Onwubere BJC, Kayani AM, Abeysinghe N, Duneas A, Tabagari S, et al: Total cardiovascular risk approach to improve efficiency of cardiovascular prevention in resource constrain settings. J Clin Epidemiol 2011, 64(12):1451-1462.

36. Foss-Freitas MC, de Andrade RC, Figueiredo RC, Pace AE, Martinez EZ, Dal Fabro AL, Franco LJ, Foss MC: Comparison of venous plasma glycemia and capillary glycemia for the screening of type 2 diabetes mellitus in the Japanese-Brazilian community of Mombuca (Guatapará-SP). Diabetol Metab Syndr 2010, 22(2):6.

Pre-publication history

The pre-publication history for this paper can be accessed here: http://www.biomedcentral.com/1471-2458/12/254/prepub

doi:10.1186/1471-2458-12-254

Cite this article as: Otgontuya et al:: Individual-based primary prevention of cardiovascular disease in Cambodia and Mongolia: early identification and management of hypertension and diabetes mellitus. BMC Public Health 2012 12:254. 